\title{
Routine Probiotics Decrease the Incidence of Necrotizing Enterocolitis in Extremely Low Birth Weight Infants < 1000 Grams
}

\author{
Stefanie Rutz ${ }^{1}$ and Luke Jardine $e^{1,2^{*}}$ \\ ${ }^{1}$ Mater Mothers' Hospital, Australia \\ ${ }^{2}$ School of Medicine, The University of Queensland, Australia
}

\begin{abstract}
Objectives: To determine the effects of routine probiotics on necrotizing enterocolitis (NEC) rates in a large tertiary Australian neonatal unit.

Methods: Retrospective cohort study of infants born $<32$ weeks of gestation between $1^{\text {st }}$ of November 2011 and $31^{\text {st }}$ of October 2013. Data were collected over two periods, before and after introduction of probiotics (Lactobacillus acidophilus and Bifidobacterium bifidum). A subgroup analysis was carried out for extremely low birth weight (ELBW) infants. Confirmed NEC was defined as stage II or more as per modified Bell's criteria. T-tests or Wilcoxon Tests were used to compare continuous variables and Chi-square or Fisher's exact test to compare categorical variables. Logistic regression was used to assess perinatal variables that might influence the risk of NEC.

Results: 297 untreated infants were compared with 283 infants who received probiotic prophylaxis. The incidence of NEC was significantly lower with probiotic treatment (4.4 versus $1.1 \%, p$-value 0.02 ). The effect was more pronounced in ELBW infants, 11 of 89 untreated infants developed confirmed NEC versus 2 of 98 exposed infants (12.4\% versus $2 \%$, $\mathrm{p}$-value 0.008$)$. There were no episodes of sepsis with the administered probiotic species.
\end{abstract}

Conclusions: Prophylactic therapy with L. acidophilus and B. bifidum resulted in a statistically significant benefit. In ELBW infants, the number needed to treat to prevent one case of NEC was 10.

Keywords

Necrotizing enterocolitis, Probiotics, Preterm infants, Extremely low birth weight infant

\section{Introduction}

Necrotizing enterocolitis (NEC) is the most common serious acquired disease of the gastrointestinal tract in preterm infants [1]. Although it can occur in full-term neonates, almost $90 \%$ of all cases occur in premature infants [2]. Both incidence and case fatality rates increase with decreasing birth weight and gestational age [2]. The majority of cases occur in very low birth weight infants with an incidence of approximately 6 to 7\% [3-5]. In ELBW infants reported NEC rates range between 10 and $11 \%$ [4-6].

The pathology of NEC is primarily due to changes from ischemic necrosis and inflammation $[7,8]$. The pathogenesis of NEC remains incompletely understood, but it is probably a heterogeneous disease resulting from multiple factors that result in mucosal injury in a susceptible host [8-10]. Factors implicated in the pathogenesis of NEC include prematurity, enteral feeding, microbial bowel overgrowth, impaired mucosal defence, excessive inflammation, circulatory instability of the intestinal tract and medications that cause intestinal mucosal injury or enhance microbial overgrowth $[2,7,11-22]$. There is strong evidence that human milk reduces the risk of NEC in premature infants [23-25]. Several risk factors have been shown to be associated with NEC, such as absent or reversed end diastolic flow, persistent ductus arteriosus (PDA), anaemia of prematurity and red blood cell transfusions, however a causal relationship has not been established [26-28]. Antenatal corticosteroids are associated with a reduction in NEC $[29,30]$.

The diagnosis of NEC is based upon the presence of the characteristic clinical features of abdominal distension and rectal bleeding, and the abdominal radiographic finding of pneumatosis intestinalis [2]. Results of laboratory evaluation, including blood studies and stool analysis, are nonspecific

*Corresponding author: Luke Jardine, Associate Professor, Mater Mothers' Hospital; School of Medicine, The University of Queensland, Brisbane, Queensland, Australia

Accepted: March 19, 2019

Published online: March 21, 2019

Citation: Rutz S, Jardine L (2019) Routine Probiotics Decrease the Incidence of Necrotizing Enterocolitis in Extremely Low Birth Weight Infants < 1000 Grams. Arch Pediatr Surg 3(1):45-52 
but may be supportive of the diagnosis of NEC [31,32]. The modified Bell staging criteria defines the different stages of NEC based upon the severity of clinical findings [33,34].

With an early diagnosis, NEC can be treated medically through cessation of feeds, use of parenteral nutrition and antibiotic treatment [2]. Although early recognition and aggressive treatment of this disorder has improved clinical outcomes, NEC accounts for a high mortality and substantial long-term morbidity in survivors of neonatal intensive care. Reported mortality rates range from 10 to $30 \%$ and also are inversely related to birth weight $[35,36] .25$ to $50 \%$ of survivors require surgical intervention [37]. Bowel perforation occurs in one third of the affected infants [1]. Stricture formation, primarily in the colon, occurs in approximately $15 \%$ of affected infants [36]. NEC is the most common cause for short bowel syndrome [38].

Probiotic bacteria are live microbial supplements that colonize the gastrointestinal tract and potentially provide benefit to the host [39]. The use of probiotic therapy has been proposed to reduce bacterial overgrowth of more invasive bacteria and promote commensal intestinal bacteria, which inhibit inflammatory pathways, thereby decreasing the risk of NEC [16]. Potential mechanisms by which probiotics may protect high risk infants from developing NEC include increased barrier to migration of bacteria across the mucosa, competitive exclusion of potential pathogens, modification of host response to microbial products, augmentation of IGA mucosal responses, enhancement of enteral nutrition that inhibits the growth of pathogens, and up-regulation of immune responses [40-44]. The most frequently used probiotics are lactobacillus and bifidobacterium [45].

To date, several meta-analyses concluded that supplementation of probiotics reduces the incidence of severe NEC and all cause mortality [45-51]. While these metaanalyses didn't reveal any significant side effects and in fact showed that the use of probiotics didn't increase the risk of sepsis $[45,46,48-50]$, there are case reports of Bifidobacterium bacteraemia in preterm infants on probiotic therapy $[52,53]$. Debate still remains about the safety of probiotics, their long term effect, the most effective preparations, as well as timing and length of therapy [54-56]. There is insufficient data with regard to the benefits of probiotic supplementation in the most at risk infants weighing less than 1000 grams at birth $[57,58]$.

\section{Methods}

Routine probiotic supplementation was introduced on the first of November 2012 for all neonates < 32 weeks of gestation. We conducted a retrospective audit of all neonates $<32$ weeks of gestation born between 1 November 2011 and 31 October 2013. Patient data were obtained from medical records and the neonatal and maternal databases of the hospital. Data were divided into two periods, period 1 (before probiotics; 1 November 2011 - 31 October 2012) and period 2 (after routine introduction of probiotics; 1 November 2012 - 31 October 2013). Infants with major congenital anomalies were excluded.
Probiotics supplementation consisted of Lactobacillus acidophilus (NCDO 1748; National Collection of Dairy Organisms) $10^{9}$ colony-forming units plus Bifidobacterium bifidum (NCDO 1453; National Collection of Dairy Organisms, Reading, United Kingdom) $10^{9}$ colony-forming units (Infloran ${ }^{\mathrm{TM}}$, Laboratorio Farmaceutico, Italy). Probiotics solution was prepared by the nursing staff using a standard method, 1 capsule of Infloran $250 \mathrm{mg}$ was dissolved in $2 \mathrm{~mL}$ of mothers' unwarmed expressed milk, donor expressed breast milk or infant formula at the bedside immediately before dose is due. The dose for preterm infants on minimal enteral feeds was one $\mathrm{mL}$ of prepared probiotics supplementation, this was increased to $2 \mathrm{~mL}$ once feeds had reached a minimum of $3 \mathrm{~mL}$ every 2 hours and continued once daily with feedings until 36 weeks' postmenstrual age.

Primary outcomes were incidence of NEC and death, secondary outcomes were time to establish full feeds, time to regain birth weight, duration of parenteral nutrition, duration of central lines and duration of hospitalization. Confirmed NEC was defined as stage II or more as per modified Bell's criteria [34].

This study was approved by the hospital research ethics committee.

\section{Statistical Analysis}

Data was assessed for normality. For continuous variables, unpaired t-test or two-sample Wilcoxon Test was applied. For categorical variables, Chi-square test of independence or Fisher's exact test was used. P-values $<0.05$ were considered statistically significant. Logistic regression was use to assess perinatal variables that might influence the risk of NEC. Statistical analysis was performed using the R and $R$ commander (http://cran.r-project.org/). If sufficient numbers were identified, we planned to do a subgroup analysis for the ELBW infants.

\section{Results}

We identified 607 premature infants born at less than 32 weeks of gestation by using existing hospital databases. 9 out of 306 infants in the control group and 15 out of 301 infants were excluded due to major congenital anomalies.

Two further infants in the treatment group had to be excluded because their charts could not be located. Neither of those two infants had confirmed NEC as per our neonatal data base however one of them died soon after birth due to severe depression at birth and hypoxic ischaemic encephalopathy. One infant in the treatment group developed confirmed NEC on day 17 of life prior to the introduction of probiotics. This baby received their first dose of probiotics at 46 days of age on the first of November 2012. This infant has been excluded from the study. Data was therefore analysed for 297 infants in the control group and 283 infants in the treatment group (Figure 1). A subgroup analysis was performed for ELBW infants, 89 infants in the control group and 98 infants in the treatment group.

Both groups had similar patient characteristics (Table 1). There were no significant differences in gestational age, birth 
Citation: Rutz S, Jardine L (2019) Routine Probiotics Decrease the Incidence of Necrotizing Enterocolitis in Extremely Low Birth Weight Infants $<1000$ Grams. Arch Pediatr Surg 3(1):45-52

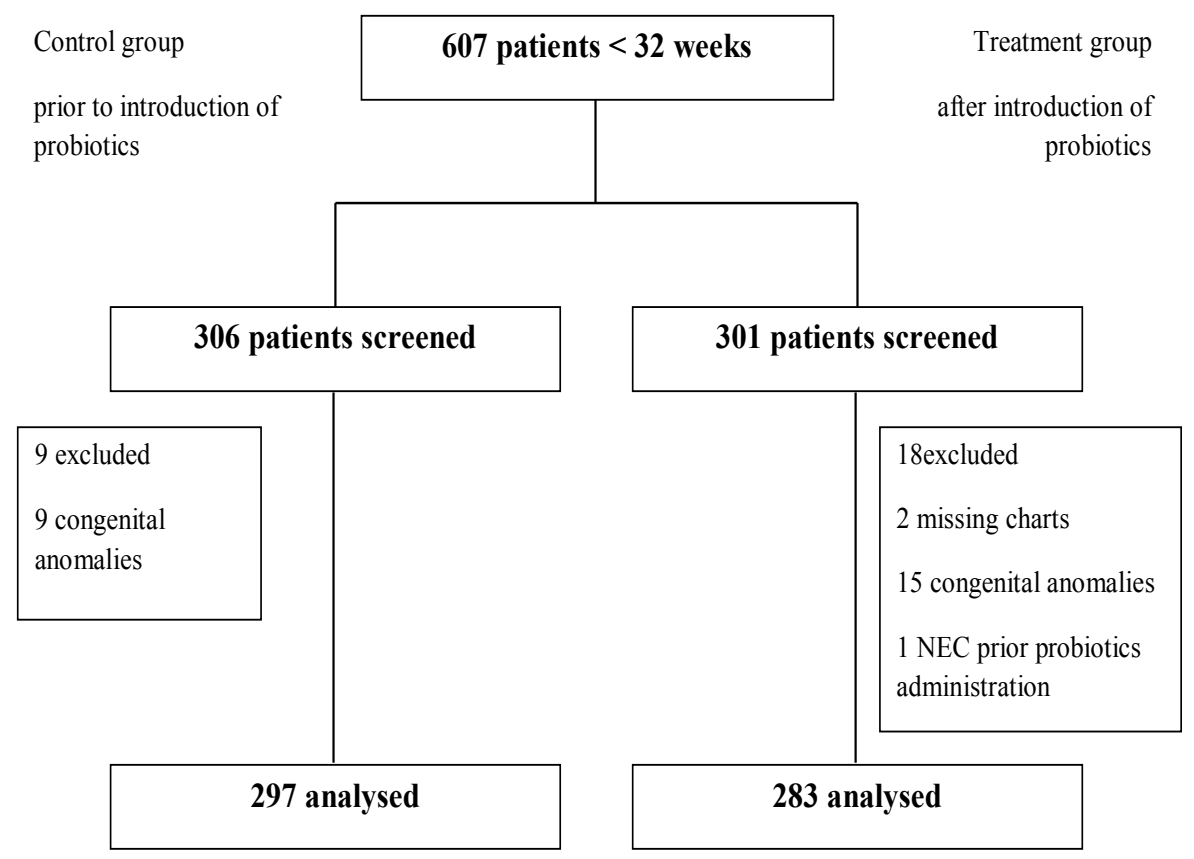

Figure 1: Subject enrolment flow chart.

Table 1: Demographic data and clinical variables.

\begin{tabular}{|c|c|c|c|c|}
\hline & & \multirow{2}{*}{\begin{tabular}{|l|} 
Period 1 \\
Control group
\end{tabular}} & \multirow{2}{*}{$\begin{array}{l}\text { Period } 2 \\
\text { Treatment group }\end{array}$} & \multirow[t]{4}{*}{ P-value } \\
\hline & & & & \\
\hline & & No probiotics & Infloran & \\
\hline & & $(N=297)$ & $(N=283)$ & \\
\hline \multicolumn{5}{|c|}{ Patient characteristics } \\
\hline \multirow{2}{*}{\multicolumn{2}{|c|}{$\begin{array}{ll}- & \text { Median GA }+ \text { (in days) (IQR 25-75\%) } \\
\text { - } & \text { Median GA (in weeks) (range) }\end{array}$}} & $189(167-208)$ & $189(163-205)$ & \multirow[t]{2}{*}{0.24} \\
\hline & & $27(23+6-29+5)$ & $27(23+2-29+2)$ & \\
\hline- & Median birth weight (in g) (IQR 25-75\%) & $940(460-1256)$ & $870(367-1185)$ & 0.16 \\
\hline- & Male (\%) & $181(60.9)$ & $171(60.4)$ & 0.90 \\
\hline - & Outborn (\%) & $34(11.4)$ & $23(8.1)$ & 0.18 \\
\hline- & APGAR score at $1 \mathrm{~min}$ (IQR $25-75 \%)$ & $6(4-8)$ & $6(4-8)$ & 0.64 \\
\hline- & APGAR score at $5 \mathrm{~min}$ (IQR 25-75\%) & $8(7-9)$ & $8(7-9)$ & 0.75 \\
\hline \multicolumn{5}{|c|}{ Maternal characteristics/delivery } \\
\hline \multicolumn{5}{|c|}{ - $\quad$ Antenatal steroids } \\
\hline & - $\quad$ Complete course (\%) & $159(53.5)$ & $174(61.5)$ & 0.12 \\
\hline & - $\quad$ Incomplete course (\%) & 56 (18.9) & $65(23)$ & \\
\hline & - $\quad$ Unknown/none (\%) & $11 / 71(27.6)$ & $6 / 38(15.5)$ & \\
\hline- & ROM $\ddagger>18$ hours prior birth (\%) & $81(27.3)$ & $86(30.4)$ & 0.41 \\
\hline- & Clinical chorioamnionitis (\%) & $27(9.1)$ & $27(9.5)$ & 0.85 \\
\hline- & Histopathological chorioamnionitis (\%) & $104(35.0)$ & 109 (38.5) & 0.38 \\
\hline- & Antepartum haemorrhage (\%) & $62(20.9)$ & $69(24.4)$ & 0.15 \\
\hline- & Pre-eclamptictoxaemia (\%) & $58(19.5)$ & $55(19.4)$ & 0.15 \\
\hline- & Spontaneous preterm labour (\%) & $190(64.0)$ & $169(59.7)$ & 0.20 \\
\hline- & Caesarean section (\%) & $211(71.0)$ & $185(65.4)$ & 0.14 \\
\hline- & Abnormal dopplers/fetal distress/non-reassuring CTG (\%) & $14(4.7)$ & $16(5.7)$ & 0.61 \\
\hline
\end{tabular}


Citation: Rutz S, Jardine L (2019) Routine Probiotics Decrease the Incidence of Necrotizing Enterocolitis in Extremely Low Birth Weight Infants $<1000$ Grams. Arch Pediatr Surg 3(1):45-52

\begin{tabular}{|c|l|l|l|}
\hline \multicolumn{2}{|l|}{} & & \\
\hline (median, IQR 25-75\%) & $2(1-2)$ & $2(1-2)$ & \\
\hline$-\quad$ Type of feeding at starting first minimal enteral feeds & & $236(83.4)$ & 0.27 \\
\hline$-\quad$ Expressed breast milk (\%) & $238(80.1)$ & $41(14.5)$ \\
\hline$\quad$ Formulaor mixed (\%) & $52(17.5)$ & $1 / 5(2.1)$ \\
\hline$-\quad$ Unknown/died & $2 / 5(2.4)$ & \\
\hline Persistent ductus arteriosus requiring treatment with Ibuprofen & & $58(20.5)$ & 0.93 \\
\hline$-\quad$ Persistent ductus arteriosus (\%) & $60(20.2)$ & \\
\hline
\end{tabular}

TGA = Gestational Age; $¥ \mathrm{ROM}=$ Rupture of Membranes.

Table 2: Primary outcomes.

\begin{tabular}{|c|c|c|c|c|}
\hline & \multirow{2}{*}{$\begin{array}{l}\text { Period } 1 \\
\text { Control group }\end{array}$} & \multirow{2}{*}{\begin{tabular}{|l|} 
Period 2 \\
Treatment group \\
\end{tabular}} & \multirow[t]{4}{*}{ P-value } & \multirow{4}{*}{$\begin{array}{l}\text { Odds ratio } \\
\text { (confidence } \\
\text { interval) }\end{array}$} \\
\hline & & & & \\
\hline & No probiotics & Infloran & & \\
\hline & $(N=297)$ & $(\mathrm{N}=\mathbf{2 8 3})$ & & \\
\hline \multicolumn{5}{|l|}{ Incidence of NEC+ (\%) } \\
\hline - $\quad$ All cases & $21(7.1)$ & $10(3.5)$ & 0.07 & $0.48(0.20-1.09)$ \\
\hline - $\quad$ Suspected NEC & $8(2.7)$ & $7(2.5)$ & 1.00 & $0.92(0.28-2.94)$ \\
\hline - $\quad$ Confirmed NEC $\geq$ stage II & $13(4.4)$ & $3(1.1)$ & 0.02 & $0.23(0.04-0.87)$ \\
\hline Incidence of death (any cause) (\%) & $20(6.7)$ & $23(8.1)$ & 0.53 & $1.22(0.63-2.41)$ \\
\hline - $\quad$ Incidence of death (secondary to NEC) & $5(1.7)$ & $2(0.7)$ & 0.45 & $0.42(0.04-2.57)$ \\
\hline
\end{tabular}

+NEC $=$ Necrotising Enterocolitis.

weight, gender, percentage of out born babies, Apgar scores, type of feeding at introduction of feeds, age at starting feeds or incidence of PDA requiring treatment with Ibuprofen.

Maternal characteristics were also similar in both groups (Table 1). There were no significant differences in the incidences of prolonged rupture of membranes, clinical or histopathological chorioamnionitis, antepartum haemorrhage, pre-eclamptic toxaemia, spontaneous onset of preterm labour and caesarean section. While administration of antenatal steroids was similar in both groups of infants < 32 weeks of gestation, there was a significant difference in the subgroup analysis of ELBW infants (48.3\% in the control group versus $69.4 \%$ in the treatment group, $p$-value 0.01 ).

The rate of confirmed NEC was significantly lower in the treatment group compared with the control group $(1.1 \%$ versus $4.4 \%, p$-value 0.02 , odds ratio 0.23 , confidence interval 0.04-0.87) (Table 2). This was also the case in the subgroup of ELBW infants ( $12.4 \%$ versus $2 \%$, p-value 0.008 , odds ratio 0.15 , confidence interval $0.02-0.71$ ). This result remained significant after performing a logistic regression to adjust for the difference in antenatal steroid administration ( $p$-value 0.03 , odds ratio 0.18 , confidence interval 0.03-0.73). According to our data, the number needed to treat to prevent one case of NEC was 30 patients. In the subgroup of ELBW infants the number needed to treat was 10.

The incidence of death was similar in both groups $16.7 \%$ in the control group versus $8.1 \%$ in the treatment group, p-value 0.53) (Table 2).
There were no statistically significant differences between the groups in time to reach full feeds, requirement and duration of parenteral nutrition, requirement and duration of central lines (umbilical venous catheter and PICC lines) or duration of hospital stay. Infants in the treatment group regained their birth weight slightly sooner than infants in the control group (median day 11 versus day 12, p 0.03) (Table 3). This was also true for ELBW infants (median day 10.4 versus day $12, \mathrm{p} 0.04)$.

\section{Discussion}

This study found that routine administration of probiotics reduces the incidence of NEC in preterm infants born at $<32$ weeks' gestation. Our baseline rate of $4.4 \%$ NEC cases in the control group was comparable to the rates described in recent randomised controlled trials (RCTs) worldwide which ranged from 2.8 to $6.5 \%$ [59-65]. Our rate was decreased to $1.1 \%$. The reduced NEC rates in the probiotic group in the majority of these RCTs ranged from 1.1 to $4.4 \%$ [60-65]. One randomised controlled trial found no cases of NEC in the probiotic group, however this could be due to relatively small sample size [59]. Our reduction in the rate of NEC from $4.4 \%$ to $1.1 \%$ is similar to a recent multicentre randomised controlled trial in Australia and New Zealand that described a decrease from $4.4 \%$ to $2 \%$ [58]. These results suggest that the reduction in the rate of NEC following administration of probiotics found in several international studies was applicable to our units' population.

A recent multicentre, randomised controlled 
Citation: Rutz S, Jardine L (2019) Routine Probiotics Decrease the Incidence of Necrotizing Enterocolitis in Extremely Low Birth Weight Infants $<1000$ Grams. Arch Pediatr Surg 3(1):45-52

Table 3: Secondary outcomes.

\begin{tabular}{|c|c|c|c|c|}
\hline & \multirow{2}{*}{\begin{tabular}{|l|} 
Period 1 \\
Control group \\
\end{tabular}} & \multirow{2}{*}{\begin{tabular}{|l|} 
Period 2 \\
Treatment group
\end{tabular}} & \multirow[t]{4}{*}{ P-value } & \multirow{4}{*}{$\begin{array}{l}95 \% \text { confidence } \\
\text { interval }\end{array}$} \\
\hline & & & & \\
\hline & No probiotics & Infloran & & \\
\hline & $(N=297)$ & $(N=283)$ & & \\
\hline \multicolumn{5}{|l|}{ Time to establish feeds (days) } \\
\hline - $\quad 50 \mathrm{mls} / \mathrm{kg} / \mathrm{d}$ (median, IQR 25-75\%) & $5(4-7)$ & $5(4-8)$ & 0.31 & - \\
\hline - $\quad 100 \mathrm{mls} / \mathrm{kg} / \mathrm{d}$ (median, IQR 25-75\%) & $7(5-10)$ & $7(5-10)$ & 0.15 & - \\
\hline - $\quad 150 \mathrm{mls} / \mathrm{kg} / \mathrm{d}$ (median, IQR $25-75 \%)$ & $8(7-11.75)$ & $9(7-12)$ & 0.32 & - \\
\hline \multicolumn{5}{|l|}{ Time to regain birth weight (days) } \\
\hline - $\quad$ (median, IQR 25-75\%) & $12(9-16)$ & $11(8-14)$ & 0.03 & $0.08-1.69$ \\
\hline \multicolumn{5}{|l|}{ Parenteral nutrition } \\
\hline - Infants requiring parenteral nutrition (\%) & $193(65.0)$ & $191(67.5)$ & 0.52 & - \\
\hline - $\quad$ Duration of parenteral nutrition (days) & $9(7-13)$ & $9(7-12)$ & 0.48 & - \\
\hline \multicolumn{5}{|l|}{ Central lines } \\
\hline$-\quad U V C+(\%)$ & $125(42.1)$ & $132(46.6)$ & 0.27 & - \\
\hline $\begin{array}{ll}\text { - } & \text { Duration UVC (days) } \\
& \text { (median, IQR 25-75\%) }\end{array}$ & $6(4-8)$ & $6(4-8)$ & 0.84 & - \\
\hline - $\quad$ PICC $\ddagger$ line $(\%)$ & $146(49.2)$ & $149(52.7)$ & 0.40 & - \\
\hline $\begin{array}{ll}-\quad & \text { Duration PICC lines (days) } \\
& \text { (median, IQR 25-75\%) }\end{array}$ & $8(7-13)$ & $8(6-13)$ & 0.58 & - \\
\hline \multicolumn{5}{|l|}{ Duration of hospitalization } \\
\hline - $\quad$ (median, IQR 25-75\%) & $58(40.25-80.75)$ & $57(41-78)$ & 0.89 & - \\
\hline
\end{tabular}

tUVC = Umbilical Venous Catheter; $¥$ PICC line = Peripherally Inserted Central Catheter.

Table 4: Confirmed NEC $\S$ cases in both groups.

\begin{tabular}{|c|c|c|c|c|c|c|c|c|}
\hline & & GA + at birth & $\begin{array}{l}\text { Birth weight } \\
\text { (gram) }\end{array}$ & NEC stage & $\begin{array}{l}\text { CGA } ¥ \text { at } \\
\text { diagnosis }\end{array}$ & $\begin{array}{l}\text { Actual age } \\
\text { at diagnosis } \\
\text { (days) }\end{array}$ & $\begin{array}{l}\text { Death secondary } \\
\text { to NEC§ }\end{array}$ & $\begin{array}{l}\text { Need for } \\
\text { surgery }\end{array}$ \\
\hline \multirow[t]{13}{*}{ Control group } & 1 & $30+0$ & 1370 & II B & $33+4$ & 25 & & No \\
\hline & 2 & $26+2$ & 946 & III A & $28+5$ & 17 & Yes & No \\
\hline & 3 & $25+0$ & 570 & III A & $28+4$ & 25 & Yes & Yes \\
\hline & 4 & $28+1$ & 520 & III B & $29+0$ & 6 & & Yes \\
\hline & 5 & $26+5$ & 960 & III A & $28+5$ & 14 & Yes & No \\
\hline & 6 & $29+5$ & 960 & III B & $35+0$ & 37 & Yes & No \\
\hline & 7 & $29+2$ & 1310 & II B & $34+1$ & 34 & & No \\
\hline & 8 & $24+5$ & 710 & III B & $26+0$ & 9 & Yes & No \\
\hline & 9 & $27+5$ & 880 & III A & $28+5$ & 7 & & No \\
\hline & 10 & $25+6$ & 824 & II A & $31+6$ & 42 & & No \\
\hline & 11 & $24+5$ & 840 & II A & $30+4$ & 41 & & No \\
\hline & 12 & $24+5$ & 734 & II B & $31+4$ & 48 & & No \\
\hline & 13 & $28+2$ & 640 & II B & $30+4$ & 16 & & No \\
\hline \multirow[t]{3}{*}{ Treatment group } & 1 & $24+0$ & 630 & II B & $29+0$ & 35 & Yes & Yes \\
\hline & 2 & $27+5$ & 940 & III B & $30+4$ & 20 & & Yes \\
\hline & 3 & $30+3$ & 1120 & III A & $37+1$ & 47 & Yes & No \\
\hline
\end{tabular}

†GA = Gestational Age; ¥CGA = Corrected Gestational Age; §NEC = Necrotising Enterocolitis; qIUGR = Intrauterine Growth Retardation. 
phase 3 study testing the effectiveness of the probiotic Bifidobacterium breve to reduce NEC, late-onset sepsis, and death was negative for all clinical outcomes [66]. This might be due to the choice and dosing of probiotic strain [56]. Interestingly, there was also a high colonisation rate of the placebo group which might have masked any benefit of the probiotic intervention [66].

In our study the majority of NEC cases occurred in ELBW infants (Table 4). This is consistent with ANZNN data that reported NEC rates of $0.8-1.2 \%$ in infants born after 28 weeks' gestation but up to $10.4 \%$ in infants born prior 28 weeks' gestation [6]. There is insufficient data with regard to the benefits of probiotic supplementation in the most at risk infants weighing less than 1000 grams at birth. To our knowledge there are only two studies that compared NEC rates in ELBW infants and neither of them could show a significant reduction $[57,58]$. This might be due to small sample size in one of the studies [57], but also due to relatively low baseline rates of NEC in the control groups of both studies [57,58]. Our study indicates that probiotics were effective in decreasing the rate of NEC in this susceptible patient group.

It is known that treatment with antenatal corticosteroids is associated with a reduction in NEC $[29,30]$. There were a higher percentage of women who received a complete course of antenatal steroids in the treatment group which could have contributed to the lower incidence of NEC. We addressed this by performing a logistic regression analysis. The incidence of NEC remained significantly lower in the treatment group after adjusting for antenatal steroid administration.

A limitation of the study is that we do not know how many babies in the cohort may have received donor breast milk. While there is strong evidence that both mothers' own milk and donor breast milk reduce the incidence of NEC compared to formula feeding, there are no trials comparing mothers' own milk and donor breast milk [23-25]. We compared the percentage of infants that received human milk only at introduction of feeds (including mothers' own milk as well as donor milk) and found no significant differences between the groups.

When probiotics were first introduced in our unit, all infants already admitted to the unit were assessed whether they met the criteria for probiotic treatment. Those who were born $<32$ weeks and had a corrected age of $<36$ weeks were commenced on probiotics as soon as parental consent had been obtained. There was one infant allocated to the treatment group who was 46 days old when probiotics were commenced but had already been diagnosed with NEC on day 17 of life. We excluded this infant from the study. Including this infant into the treatment group on an intention to treat basis still showed a significant reduction in the incidence of NEC ( $1.4 \%$ versus $4.4 \%$, p-value 0.047 , odds ratio 0.31 , confidence interval 0.07-1.03).

Debate still remains about the safety of probiotics $[54,56]$. While several meta-analyses didn't reveal any significant side effects $[45,46,48-50]$, there are case reports of Bifidobacterium bacteraemia in preterm infants on probiotic therapy $[52,53]$. In our study, reassuringly there were no confirmed episodes of sepsis with the administered probiotic species.
There is ongoing controversy about the most effective preparations of probiotics, as well as timing and length of therapy [55]. The available studies do not focus on one specific product or dosing regimen, however both the administration of Lactobacillus species and a mixture of probiotics significantly reduced the incidence of severe stage II to III NEC in several trials [45]. Infloran has previously been used in randomised controlled trials with good effect $[62,63]$. According to our data, the number needed to treat to prevent one case of NEC was 30 patients. In the subgroup of ELBW infants the number needed to treat was 10 . In conclusion, routine administration of probiotics was effective in decreasing the incidence of NEC in very low and extremely low birth weight infants in our population. Other Australian units should also consider its use for the prevention of NEC.

\section{References}

1. Kafetzis DA, Skevaki C, Costalos C (2003) Neonatal necrotizing enterocolitis: An overview. Current Opinion in Infectious Diseases 16: 349-355.

2. Maheshwari A, Carlo WA (2015) Digestive system disorders. In: Kliegman R, Stanton B, St Geme J, Schor N. Nelson Textbook of Pediatrics Expert Consult. (20 $0^{\text {th }}$ edn), Elsevier Health Sciences, London.

3. Horbar JD, Badger GJ, Carpenter JH, et al. (2002) Trends in mortality and morbidity for very low birth weight infants, 19911999. Pediatrics 110: 143-151.

4. Lee SK, McMillan DD, Ohlsson A, et al. (2000) Variations in practice and outcomes in the Canadian NICU network: 19961997. Pediatrics 106: 1070-1079.

5. Sankaran K, Puckett B, Lee DS, et al. (2004) Variations in incidence of necrotizing enterocolitis in Canadian neonatal intensive care units. J Pediatr Gastroenterol Nutr 39: 366-372.

6. Chow S, Marsney R, Hossain S, et al. (2013) Report of the Australian and New Zealand neonatal network 2010, ANZNN, Sydney, Australia.

7. Ballance WA, Dahms BB, Shenker N, et al. (1990) Pathology of neonatal necrotizing enterocolitis: A ten-year experience. J Pediatr 117: S6-S13.

8. Huda S, Chaudhery S, Ibrahim H, et al. (2014) Neonatal necrotizing enterocolitis: Clinical challenges, pathophysiology and management. Pathophysiology 21: 3-12.

9. Kliegman RM, Walker WA, Yolken RH (1993) Necrotizing enterocolitis: Research agenda for a disease of unknown etiology and pathogenesis. Pediatric research 34: 701-708.

10. Neu J (1996) Necrotizing enterocolitis: The search for a unifying pathogenic theory leading to prevention. Pediatr Clin North Am 43: 409-432.

11. Cotten CM, Taylor S, Stoll B, et al. (2009) Prolonged duration of initial empirical antibiotic treatment is associated with increased rates of necrotizing enterocolitis and death for extremely low birth weight infants. Pediatrics 123: 58-66.

12. Guillet R, Stoll BJ, Cotten CM, et al. (2006) Association of H2blocker therapy and higher incidence of necrotizing enterocolitis in very low birth weight infants. Pediatrics 117: e137-e142.

13. Berseth CL (2005) Feeding strategies and necrotizing enterocolitis. Curr Opin Pediatr 17: 170-173. 
Citation: Rutz S, Jardine L (2019) Routine Probiotics Decrease the Incidence of Necrotizing Enterocolitis in Extremely Low Birth Weight Infants $<1000$ Grams. Arch Pediatr Surg 3(1):45-52

14. Clark DA, Miller MJ (1990) Intraluminal pathogenesis of necrotizing enterocolitis. J Pediatr 117: S64-S67.

15. De Plaen IG (2013) Inflammatory signaling in necrotizing enterocolitis. Clin Perinatol 40: 109-124.

16. Hunter CJ, Upperman JS, Ford HR, et al. (2008) Understanding the susceptibility of the premature infant to necrotizing enterocolitis (NEC). Pediatr Res 63: 117-123.

17. Kandasamy J, Huda S, Ambalavanan N, et al. (2014) Inflammatory signals that regulate intestinal epithelial renewal, differentiation, migration and cell death: Implications for necrotizing enterocolitis. Pathophysiology 21: 67-80.

18. Morowitz MJ, Poroyko V, Caplan M, et al. (2010) Redefining the role of intestinal microbes in the pathogenesis of necrotizing enterocolitis. Pediatrics 125: 777-785.

19. Nowicki $P(1990)$ Intestinal ischemia and necrotizing enterocolitis. J Pediatr 117: S14-S19.

20. Ramani M, Ambalavanan N (2013) Feeding practices and necrotizing enterocolitis. Clin Perinatol 40: 1-10.

21. Schanler RJ, Shulman RJ, Lau C (1999) Feeding strategies for premature infants: Beneficial outcomes of feeding fortified human milk versus preterm formula. Pediatrics 103: 1150-1157.

22. Stewart CJ, Marrs ECL, Magorrian S, et al. (2012) The preterm gut microbiota: Changes associated with necrotizing enterocolitis and infection. Acta Paediatr 101: 1121-1127.

23. Lucas A, Cole TJ (1990) Breast milk and neonatal necrotising enterocolitis. Lancet 336: 1519-1523.

24. Meinzen-Derr J, Poindexter B, Wrage L, et al. (2009) Role of human milk in extremely low birth weight infants' risk of necrotizing enterocolitis or death. J Perinatol 29: 57-62.

25. Quigley M, McGuire W (2014) Formula versus donor breast milk for feeding preterm or low birth weight infants. Cochrane Database Syst Rev.

26. Dollberg S, Lusky A, Reichman B (2005) Patent ductus arteriosus, indomethacin and necrotizing enterocolitis in very low birth weight infants: A population-based study. J Pediatr Gastroenterol Nutr 40: 184-188.

27. Dorling J, Kempley S, Leaf A (2005) Feeding growth restricted preterm infants with abnormal antenatal doppler results. Arch Dis Child Fetal Neonatal Ed 90: 359-363.

28. Singh R, Shah BL, Frantz ID 3rd (2012) Necrotizing enterocolitis and the role of anemia of prematurity. Semin Perinatol 36: 277 282.

29. Roberts D, Dalziel S (2006) Antenatal corticosteroids for accelerating fetal lung maturation for women at risk of preterm birth. Cochrane Database Syst Rev.

30. Wong D, Abdel-Latif M, Kent A (2014) Antenatal steroid exposure and outcomes of very premature infants: A regional cohort study. Arch Dis Child Fetal Neonatal Ed 99: 12-20.

31. Hällström M, Koivisto $A M$, Janas M, et al. (2006) Laboratory parameters predictive of developing necrotizing enterocolitis in infants born before 33 weeks of gestation. J Pediatr Surg 41: 792-798.

32. Kenton AB, O'Donovan D, Cass DL, et al. (2005) Severe thrombocytopenia predicts outcome in neonates with necrotizing enterocolitis. J Perinatol 25: 14-20.

33. Bell MJ, Ternberg JL, Feigin RD, et al. (1978) Neonatal necrotizing enterocolitis. Therapeutic decisions based upon clinical staging. Ann Surg 187: 1-7.

34. Kliegman RM, Walsh MC (1987) Neonatal necrotizing enterocolitis: Pathogenesis, classification, and spectrum of illness. Curr Probl Pediatr 17: 213-288.

35. Fitzgibbons SC, Jaksic T, Ching Y, et al. (2009) Mortality of necrotizing enterocolitis expressed by birth weight categories. J Pediatr Surg 44: 1072-1076.

36. Sinha S, Miall L, Jardine L (2016) Essential neonatal medicine. John Wiley \& Sons. ( $6^{\text {th }}$ edn), Chichester, West Sussex, England.

37. Kastenberg ZJ, Sylvester KG (2013) The surgical management of necrotizing enterocolitis. Clin Perinatol 40: 135-148.

38. Gutierrez IM, Kang KH, Jaksic T (2011) Neonatal short bowel syndrome. Seminars in Fetal and Neonatal Medicine 16: 157163.

39. Fuller R (1989) Probiotics in man and animals. J Appl Bacteriol 66: 365-378.

40. Link-Amster H, Rochat F, Saudan KY, et al. (1994) Modulation of a specific humoral immune response and changes in intestinal flora mediated through fermented milk intake. FEMS Immunol Med Microbiol 10: 55-63.

41. Martin CR, Walker WA (2008) Probiotics: Role in pathophysiology and prevention in necrotizing enterocolitis. Semin Perinatol 32: 127-137.

42. Millar M, Wilks M, Costeloe K (2003) Probiotics for preterm infants? Arch Dis Child Fetal Neonatal Ed 88: 354-358.

43. Mattar AF, Drongowski RA, Coran AG, et al. (2001) Effect of probiotics on enterocyte bacterial translocation in vitro. Pediatr Surg Int 17: 265-268.

44. Reid G, Howard J, Gan BS (2001) Can bacterial interference prevent infection? Trends Microbiol 9: 424-428.

45. AlFaleh K, Anabrees J (2014) Probiotics for prevention of necrotizing enterocolitis in preterm infants. Cochrane Database Syst Rev.

46. Deshpande G, Rao S, Patole S, et al. (2010) Updated metaanalysis of probiotics for preventing necrotizing enterocolitis in preterm neonates. Pediatrics 125: 921-930.

47. Bernardo WM, Aires FT, Carneiro RM, et al. (2013) Effectiveness of probiotics in the prophylaxis of necrotizing enterocolitis in preterm neonates: A systematic review and meta-analysis. J Pediatr (Rio J) 89: 18-24.

48. Guthmann F, Kluthe C, Buhrer C (2010) Probiotics for prevention of necrotising enterocolitis: An updated meta-analysis. Klin Padiatr 222: 284-290.

49. Wang Q, Dong J, Zhu Y (2012) Probiotic supplement reduces risk of necrotizing enterocolitis and mortality in preterm very low-birth-weight infants: An updated meta-analysis of 20 randomized, controlled trials. J Pediatr Surg 47: 241-248.

50. Yang Y, Guo Y, Kan Q, et al. (2014) A meta-analysis of probiotics for preventing necrotizing enterocolitis in preterm neonates. Braz J Med Biol Res 47: 804-810.

51. Mihatsch WA, Braegger CP, Decsi T, et al. (2012) Critical systematic review of the level of evidence for routine use of probiotics for reduction of mortality and prevention of necrotizing enterocolitis and sepsis in preterm infants. Clin Nutr 31: 6-15. 
52. Bertelli C, Pillonel T, Torregrossa A, et al. (2015) Bifidobacterium longum bacteremia in preterm infants receiving probiotics. Clin Infect Dis 60: 924-927.

53. Zbinden A, Zbinden R, Berger C, et al. (2015) Case series of bifidobacterium longum bacteremia in three preterm infants on probiotic therapy. Neonatology 107: 56-59.

54. Ofek Shlomai N, Deshpande G, Rao S, et al. (2014) Probiotics for preterm neonates: What will it take to change clinical practice? Neonatology 105: 64-70.

55. Deshpande GC, Rao SC, Keil AD, et al. (2011) Evidence-based guidelines for use of probiotics in preterm neonates. BMC Med 9: 92.

56. Abrahamsson TR (2016) Not all probiotic strains prevent necrotising enterocolitis in premature infants. Lancet 387: 624625.

57. Al-Hosni M, Duenas M, Hawk M, et al. (2012) Probioticssupplemented feeding in extremely low-birth-weight infants. J Perinatol 32: 253-259.

58. Jacobs SE, Tobin JM, Opie GF, et al. (2013) Probiotic effects on late-onset sepsis in very preterm infants: A randomized controlled trial. Pediatrics 132: 1055-1062.

59. Braga TD, da Silva GA, de Lira PI, et al. (2011) Efficacy of bifidobacterium breve and lactobacillus casei oral supplementation on necrotizing enterocolitis in very-low-birthweight preterm infants: A double-blind, randomized, controlled trial. Am J Clin Nutr 93: 81-86.
60. Dani C, Biadaioli R, Bertini G, et al. (2002) Probiotics feeding in prevention of urinary tract infection, bacterial sepsis and necrotizing enterocolitis in preterm infants. A prospective double-blind study. Biol Neonate 82: 103-108.

61. Demirel G, Erdeve O, Celik IH, et al. (2013) Saccharomyces boulardii for prevention of necrotizing enterocolitis in preterm infants: A randomized, controlled study. Acta Paediatr 102: e560-e565.

62. Lin $\mathrm{HC}$, Hsu CH, Chen HL, et al. (2008) Oral probiotics prevent necrotizing enterocolitis in very low birth weight preterm infants: A multicenter, randomized, controlled trial. Pediatrics 122: $693-700$

63. Lin HC, Su BH, Chen AC, et al. (2005) Oral probiotics reduce the incidence and severity of necrotizing enterocolitis in very low birth weight infants. Pediatrics 115: 1-4.

64. Manzoni P, Rinaldi M, Cattani S, et al. (2009) Bovine lactoferrin supplementation for prevention of late-onset sepsis in very lowbirth-weight neonates: A randomized trial. JAMA 302: 14211428.

65. Rojas MA, Lozano JM, Rojas MX, et al. (2012) Prophylactic probiotics to prevent death and nosocomial infection in preterm infants. Pediatrics 130: e1113-e1120.

66. Costeloe K, Hardy P, Juszczak E, et al. (2016) Bifidobacterium breve BBG-001 in very preterm infants: A randomised controlled phase 3 trial. Lancet 387: 649-660. 